\title{
A construção de um glossário de topônimos latinos no Brasil
}

\author{
Lucia Pestana Silva*, Fábio Frohwein de Salles Moniz ${ }^{* *}$
}

RESUMO: Objetivamos, neste artigo, expor o processo de elaboração de um glossário de topônimos latinos no Brasil, a partir de dados coletados em "Historia navigationis in Brasiliam” (LÉRY, 1586). A construção de um glossário específico (BORBA, 2003) busca facilitar o trabalho de profissionais que lidam com obras raras, pesquisadores e historiadores que trabalham com as obras ou assuntos abrangidos no léxico apresentado com o glossário. Apresentaremos os estudos preliminares necessários e relevantes no processo de elaboração do glossário proposto com os dados pesquisados na obra mencionada.

Palavras-chave: glossário latino; Humanismo; léxico latino; Historia navigationis; topônimos.

\section{The proposal of a glossary of Latin toponyms in Brazil}

ABSTRACT: We aim to present the process of elaborating a glossary of Latin toponyms in Brazil, based on data collected in "Historia navigationis in Brasiliam" (LÉRY, 1586). The construction of a specific glossary (BORBA, 2003) aims to make easier the work of those who deal with rare works, researchers and historians who deal with the works or subjects covered in the lexicon presented with the glossary. We will present the preliminary studies that are necessary and relevant in the process of elaboration of the proposed glossary with the data researched in the mentioned work.

Keywords: Latin glossary; Humanism; Latin lexicon; Historia navigationis; toponyms.

\section{Introdução}

No Brasil, é fácil depararmo-nos com obras $\operatorname{raras}^{1}$ em latim no acervo de diversas instituições. Difícil é compreendê-las, sobretudo, pelo fato de que a língua

\footnotetext{
*Graduanda em Letras Português-Latim pela Universidade Federal do Rio de Janeiro.

** Possui Graduação em Latim (1999), Doutorado (2010) em Literatura Brasileira pela Universidade Federal do Rio de Janeiro e Doutorado (2018) em Letras Clássicas pela mesma instituição, onde atualmente é Professor Adjunto de Língua e Literatura Latinas, em regime de 40 horas semanais com dedicação exclusiva. Atuante em crítica textual, investiga a transmissão da literatura latina em edições modernas, com especial interesse na obra de Catulo, Tibulo e Propércio. Dedica-se ainda ao estudo e tradução de autores novilatinos, orientando pesquisas em nível de Graduação e Pós-Graduação. Coordena o projeto de extensão Núcleo de Documentação em Línguas Clássicas junto à Fundação Biblioteca Nacional, para a otimização de descrições de obras raras em latim e grego integrantes do Catálogo do patrimônio Bibliográfico Nacional (CPBN).

${ }^{1}$ Compreendemos como "obra rara" o livro que segue os critérios estabelecidos pelo Plano Nacional de Recuperação de Obras Raras (PLANOR), fundado em 1983 pela portaria no 19 da Secretaria da Cultura. Uma de suas funções é fornecer orientações sobre procedimentos técnicos na identificação, organização, tratamento técnico e gestão de acervos de obras raras. Os parâmetros para classificação de um livro como obra rara são os seguintes: 1) Primeiras impressões (séc. XV - XVI); 2) Impressões dos séc. XVII e XVIII; 3) Impressões brasileiras do séc. XIX; 4) Edições clandestinas; 5) Edições de tiragens reduzidas; 6) Edições
} 
latina foi progressivamente afastada do ensino básico após a Lei de Diretrizes e Bases $\mathrm{n}^{\circ}$ 4024 de $1961 .^{2}$ Infelizmente, no Brasil, as obras raras são superestimadas enquanto objetos de compra ou de beleza estética, deixando-se de lado a importância do seu conteúdo. Por vezes, são esquecidas por completo por estarem escritas em línguas cujo aprendizado não é oferecido no sistema regular de ensino, a exemplo dos idiomas clássicos.

Embora a língua latina seja um idioma sem falantes nativos há séculos, sua disseminação foi de suma importância principalmente para o Ocidente. Até os dias de hoje, o latim é relevante não só para a leitura de autores clássicos da Roma antiga, mas também para a compreensão de termos técnicos em diversas áreas do conhecimento, como zoologia, botânica, matemática, astronomia, entre outras. No entanto, o ensino do latim está cada vez mais ausente das instituições de ensino do Brasil, o que impossibilita os próprios cidadãos brasileiros de lerem e compreenderem obras, inscrições e expressões em língua latina que se encontram em seu país.

O latim foi a língua empregada no século XVI para a circulação dos relatos sobre as grandes descobertas e aventuras vividas por viajantes, quando estes almejavam que seus escritos pudessem ser lidos no mundo pela elite que compreendia o idioma. A ampliação de conhecimentos e saberes apenas foi possível graças ao fato de o latim ter sido, no mundo ocidental, a língua de cultura de diferentes povos. Por isso mesmo, autores, escritores, viajantes e aventureiros escreviam em latim ou vertiam suas obras para o latim para poderem, dessa forma, ter uma maior veiculação, compreensão e divulgação de documentos, livros, cartas, relatos, diários e tudo mais que pudesse ser mencionado. Para Briesemeister: "o latim era talvez especialmente útil em 'popularizar'(...) livros escritos originalmente em línguas românicas." (BRIESEMEISTER, 1983 in BURKE, 2009, p. 82).

Nesse sentido, este artigo apresenta os primeiros resultados da pesquisa de Iniciação Científica em andamento ${ }^{3}$, que objetiva levantar palavras e expressões em latim relacionadas ao território brasileiro. Para tal, será utilizado como corpus de investigação a obra de Jean de Léry, "Historia navigationis in Brasiliam" (HNB) (1586). Nosso objetivo geral será analisar nesse documento: 1) a revitalização do latim durante o Renascimento, por meio de neologismos latinos de forma ou de sentido ou da latinização de vocábulos oriundos de outros idiomas; e 2) a influência latina nos atuais topônimos de cidades, estados, rios e demais elementos referentes ao Brasil.

Objetivamos, especificamente, a elaboração de um glossário bilíngue (latimportuguês) dos topônimos investigados no projeto, correlacionando-os com a atual situação geopolítica brasileira. O glossário servirá de subsídio para pesquisadores e profissionais que se envolvam com temas relacionados ao assunto da pesquisa. A escolha de $H N B$, como corpus de investigação, deu-se pelo fato de este apresentar uma quantidade variada e significativa de topônimos e neologismos relacionados ao território brasileiro.

\section{Contextualização}

especiais (de luxo para bibliófilos); 7) Exemplares de coleções especiais (regra geral com belas encadernações e ex-libris); 8) Exemplares com anotações manuscritas de importância (incluindo dedicatórias); 9) Obras esgotadas.

${ }^{2}$ Veja-se AMARANTE, 2017.

${ }^{3}$ A pesquisa encontra-se, neste momento, em fase de leituras teóricas e de levantamento e análise dos dados do corpus selecionado. 
Jean de Léry foi um viajante francês que decidiu acompanhar um grupo de protestantes missionários no ano de 1556 até o Novo Mundo. O destino específico da viagem era a França Antártica, colônia francesa estabelecida na Baía de Guanabara pelo também francês Nicolas Durand de Villegagnon, que contava com o apoio financeiro de Gaspar de Colligni, autoridade francesa convertida ao calvinismo. Já no Brasil, Léry, além de se deleitar com as paisagens maravilhosas encontradas em território brasileiro, também conviveu com tribos indígenas, conhecendo seus costumes, rituais, comidas, utensílios, enfeites entre outras coisas. ${ }^{4}$

Foram, portanto, as maravilhas do Novo Mundo e suas descobertas que impulsionaram o francês a relatar em forma de livro sua viagem desde a partida da Europa até a chegada ao Brasil. Primeiramente publicada em francês, em 1578, a obra seria impressa em língua latina somente no ano de 1586.

A primeira edição latina é composta de 447 páginas, não numeradas do início ao fim. A paginação apenas é indicada a partir do texto que narra propriamente as experiências de Léry na vinda ao Brasil, o que corresponde a 341 páginas divididas em 22 capítulos, cada qual iniciado com uma capitular e uma iluminura. Porém, além dessas páginas, acrescem-se, à primeira edição latina, uma seção intitulada epistola, quatro commentarii ("comentários"), um praefatio ("prefácio"), um praefatio capitulorum ("prefácio dos capítulos"), um psalmum ("salmo"), uma errata ("erros") e um index ("índice"), todos inteiramente em latim.

Também podemos perceber que, ao longo dessa mesma edição latina, as palavras usadas como neologismos ou topônimos são exemplificadas ou explicadas, em latim, em marginálias. Outro componente paratextual são as sete gravuras ao longo do livro, que expressam a visão do europeu acerca do índio, de seus costumes e da natureza.

\section{Primeiros estudos}

Para esta pesquisa, consideramos que a elaboração de um glossário é um trabalho lexicográfico específico, podendo ser voltado para um recorte temporal ou contextual servindo de ferramenta para observação e compreensão de vocábulos. Buscamos definir atributos semânticos, morfossintáticos e pragmáticos dos vocábulos selecionados, observando não apenas suas construções estruturais, mas também observações situacionais. Sendo assim, o estudo de natureza lexicográfica, a exemplo de glossários técnicos ou temáticos, feito a partir dos usos vocabulares, proporciona ao leitor informações importantes, como nos alerta Borba (2003, p. 17):

Uma investigação que tencione levantar propriedades sintáticosemânticas do léxico tem que começar por verificar quais são as grandes linhas de circulação vocabular em todos ou num registro determinado das duas modalidades básicas de manifestação da língua: o oral e o escrito. A primeira impressão que se tem é de dispersão ou de difusão um tanto desordenada ou arbitrária, que dá lugar, em seguida, à percepção de uma estreita relação texto/contexto associada à variação de acepções.

Embora alguns estudiosos considerem o trabalho lexicográfico como uma tarefa de proporções práticas, sua produção exige um cuidado especial por parte de seu elaborador. Não se trata apenas de listar palavras e seus sinônimos, mas de transmitir

\footnotetext{
${ }^{4}$ Veja-se MARIZ; PROVENÇAL, 2015.
} 
conceitos claros e inerentes ao receptor. Antes que se possa concluir um glossário ou um dicionário, é necessário que se faça um trabalho lexicológico. Portanto, as acepções levantadas para cada léxico devem ser pesquisadas e conferidas de acordo com o estudo do uso semântico e circunstancial da língua em questão.

Considerando a língua como um meio de comunicação que objetiva, por parte de seu falante interlocutor, transmitir sentido da forma mais clara possível, a busca por informações pragmáticas pode ser de fundamental importância para o entendimento de um emprego lexical. Por outro lado, o conhecimento gramatical da língua internalizada auxilia na compreensão de derivações, flexões mórficas e, de uma forma geral, dos termos gramaticais que são facilmente reconhecidos pelo falante receptor.

Com base em nosso corpus, percebemos que, geralmente, vocábulos sem correspondentes no português são específicos do tupi antigo e designam uma comunidade, costumes, objetos, animais ou mesmo alimentos. Trata-se, portanto, de conceitos de uma determinada cultura local, como por exemplo: Araroye, tipo de adorno feito de penas de avestruz usado no corpo pelos índios tupis; Trayetic, nome da cera utilizada na ornamentação corporal. Não se encontra uma palavra em português que tenha significado correspondente para tais objetos. Sendo assim, sua definição é feita a partir da sua funcionalidade e de suas características físicas.

\section{Primeiras questões}

Até o momento, analisamos a epístola inicial e os dez primeiros capítulos do corpus. Neste início da pesquisa, percebemos a importância de atentarmos para os recursos braquigráficos em geral, uma vez que esses expedientes de escrita são recorrentes na época de Léry e, se negligenciados, podem inviabilizar a análise ou, até mesmo, a compreensão do texto. Portanto, acrescentamos aos temas pesquisados um estudo paleográfico no corpus de análise. ${ }^{5}$

Até os dias de hoje, os recursos braquigráficos são elementos muito utilizados em textos tanto formais quanto informais. No texto que se refere esta pesquisa, além do ponto final, foram usados traços gerais abreviativos sobrepostos às letras, símbolos e siglas que exerciam a função de abreviar um vocábulo. Portanto, fez-se necessário um levantamento dos traços gerais e dos símbolos abreviativos para a análise das peculiaridades de escrita na $1^{\text {a }}$ edição latina de $H N B$, conforme a tabela 1 :

\begin{tabular}{|c|c|c|}
\hline PÁGINA & PECULIARIDADES & PALAVRA DESENVOLVIDA \\
\hline$[2]$ & Celf. & Cels[itudine] \\
\hline 5 & Brafiliêfes & Brasilienses \\
\hline 110 & factũ & factum \\
\hline 184 & àquibus & a quibus \\
\hline 91 & ègoffypio & egossypio \\
\hline 269 & twe & tuae \\
\hline 112 & breuifsimam & breuissimam \\
\hline 115 & adimítg & adimitq[ue] \\
\hline 120 & vtq́que & utque \\
\hline 120 & hấc: & hac \\
\hline 23 & Reibrimaris & Rubri maris \\
\hline
\end{tabular}

${ }^{5}$ Veja-se LOPES et alii, 2017. 


\begin{tabular}{|l|c|l|}
\hline 115 & $\boldsymbol{8}$ & et \\
\hline$[1]$ & $\dot{\boldsymbol{\sigma}}$ & et \\
\hline 118 & quib & quibus \\
\hline
\end{tabular}

Tabela 1 - Dados braquigráficos do corpus.

Fonte: LÉRY, $1586 .^{6}$

Neste trabalho, verificamos que um traço abreviativo também pode indicar uma determinada classe gramatical. É o caso do traço indicativo de preposição, conjunção ou advérbio, isto é, de palavras não declináveis. Vejamos os exemplos a seguir:

2 cùm : preposição de abl: "com”; “em companhia de”. (LÉRY, 1586, p. 121).

3 quòd : conjunção: "quanto a este fato"; "a saber"; "pelo fato de". (LÉRY, 1586, p. 122).

${ }_{4}$ Latinè : advérbio: "em latim"; “corretamente”; “em bom latim”. (LÉRY, 1586, p. 271).

Salientamos que nosso estudo acerca dos recursos braquigráficos em $H N B$ não reflete qualquer pretensão de fazermos uma transcrição diplomática ${ }^{7}$ da obra em questão. Por outro lado, é inegável que a familiaridade com esses expedientes de escrita seja fundamental para a compreensão das palavras que integrarão o glossário a que nos propomos elaborar. Dessa forma, procedemos ao levantamento e à análise de todos os recursos braquigráficos em $H N B$ para fins de sistematizarmos seu uso.

\section{Primeiros resultados}

Ao longo da elaboração do glossário proposto, nosso levantamento de dados levou em consideração as flexões de número/caso de cada topônimo em $H N B$, ou seja, suas diversas manifestações morfossintáticas. Com isso, buscamos depreender as informações mínimas e necessárias para a composição de verbetes de substantivos ou adjetivos, como, por exemplo, genitivo, gênero e classe gramatical ${ }^{8}$ Porém, descartamos da contagem as repetições de uma mesma forma com que um determinado vocábulo aparece no corpus. Vejamos um exemplo:

Denique efferati Ouetacates illi (...). ${ }^{9}$ (LÉRY, 1586, p. 37).

\footnotetext{
${ }^{6}$ As normas gerais de transcrição adotadas neste trabalho são as seguintes: 1)abreviaturas sinalizadas por ponto final (.) foram desenvolvidas entre colchetes [ ]; 2) abreviaturas sem marcação foram desenvolvidas entre colchetes [ ]; 3) o traço geral abreviativo $\tilde{\mathbf{u}}$ foi desenvolvido logo em seguida a letra na qual o traço está sobreposto por consoante nasal $\langle\mathrm{n}\rangle$ ou $\langle\mathrm{m}\rangle$; 4) o traço sobreposto $\boldsymbol{e}$ indica classe gramatical de preposição ou advérbio e não é representado na transcrição; 4) ${ }^{\mathbf{Q}} \mathbf{1}$ foi desenvolvido pelo ditongo latino <ae>;5) unificamos a representação de $\mathbf{f} \mathbf{e}$ e $\mathbf{s}$ por $\langle s>$; 6) o traço sobreposto :q́ue sinaliza um recurso gramatical da língua latina (uso da partícula -que) e não foi utilizado recurso de transcrição para o traço; 7) o traço sobreposto $\mathbf{a}$ indica uma sílaba longa e não foi utilizado recurso de transcrição para o traço; 8) separamos por espaço palavras que claramente foram unificadas de acordo com consulta ao dicionário latino: Rribrmaris,<Rubri maris>; 9) unificamos a representação de $\boldsymbol{\&}$ e $\dot{\mathcal{O}}$ por <et>; 10) o recurso abreviativo $\bullet$ foi transcrito como $<$ us $>$.

${ }^{7}$ Uma edição diplomática é aquela que interpreta e reproduz o texto original com fidelidade.

${ }^{8}$ Veja-se FARIA, 1958.

${ }^{9}$ Finalmente, aqueles Uetacás selvagens (...). Todas as traduções do latim apresentadas aqui são de nossa autoria.
} 


\section{(...)cogitantcum Ouetacatibusnegotiationem (...). ${ }^{10}$ (LÉRY, 1586, p. 38).}

Nos exemplos acima, verificamos os vocábulos Ouetacas e Ouetacatibus. O primeiro encontra-se no nominativo singular (sujeito da oração). Já o segundo está no ablativo plural (adjunto adverbial). Podemos afirmar, a partir da técnica de comutação ${ }^{11}$, que se trata de um substantivo feminino de terceira declinação com tema em dental surda, a exemplo de vocábulos do latim clássico como aetas, aetatis; ciuitas, ciuitatis; dignitas, dignitatis; entre outros. Dessa forma, propomos, para a palavra em destaque nos excertos supracitados, a seguinte entrada de verbete: Ouetacas, -atis s.f.

Com relação ao significado de Ouetacas, utilizamos, como fonte de informação para palavras oriundas do tupi, o Dicionário tupi (antigo) português (CARVALHO, 1987). De acordo com Silva (1983 in CARVALHO, 1987, p. XX), "no que tange ao tupi, este idioma foi e é o mais estudado entre nós, não somente por ter sido considerado uma língua geral ou a mais falada no passado, como também pelos estudos linguísticos ou históricos da origem dos topônimos". Vejamos, agora, o verbete completo contendo a entrada de Ouetacas e sua acepção:

Ouetacas, -atis s.f. Uetacá, Goitacá, Guaitaká. Tribo inimiga dos Tupinambás, localizados na extensão dos rios Paraíba do Sul e do rio Macaé. Por esse povo ser encontrado em uma das regiões do interior do Rio de Janeiro, originou-se o nome do local atualmente conhecido como Campos dos Goytacazes. Do tupi: guai-t-aka.

A forma do verbete acima segue as mesmas informações relevantes que um dicionário da língua latina apresenta para a identificação e compreensão de substantivos latinos: nominativo singular (Ouetacas); genitivo singular (Ouetacatis), classe gramatical representada por s. (substantivo), gênero representado por f. (feminino) e, por fim, sua definição. Sempre que possível, inserimos também a origem do verbete.

No entanto, nem sempre podemos propor, com precisão, a entrada de um topônimo ou de um neologismo pelo fato de ele aparecer apenas uma vez no texto, o que nos impossibilita inferir qual seria seu genitivo e, consequentemente, sua declinação/paradigma. Há, ainda, casos de topônimos ou neologismos que apresentam várias ocorrências em $H N B$, mas com a mesma forma em funções sintáticas diferentes. ${ }^{12}$ Sendo assim, decidimos considerar indeclináveis ambos os tipos de vocábulos. Vejamos a seguir dois exemplos de topônimos:

Boucan indecl. Grelha de madeira usada para tostar carnes. Do tupi: mo-kaẽ.

\footnotetext{
${ }^{10}$ (...) projetam negócio com os Uetacás (...).

${ }^{11}$ Análise e compreensão de formas mínimas que constituem o vocábulo formal unitário, ou seja, uma análise mórfica na qual se procede à descrição de formas de uma língua dada: "por esse nome [comutação] se entende a substituição de uma invariante por outra, de que resulta um novo vocábulo formal." (CAMARA JR, 1972, p.62).

12 São os casos de vocábulos que, por vezes, aparecem em diferentes funções sintáticas, porém sem variação de terminação da palavra. Nesse sentido, deveria ser usada uma desinência de caso diferente para cada função de acordo com alguma declinação latina. No entanto, não é o que constatamos com algumas palavras. Podemos dar como exemplo o topônimo maraca. No texto ele aparece como sujeito (nominativo), mas também aparece como objeto indireto (dativo), como objeto direto (acusativo) e ainda como adjunto adverbial (ablativo), mas em todas as ocorrências, foi escrito com a mesma morfologia, o que nos garante chamar de um vocábulo empregado como indeclinável.
} 
Cay indecl. Macaco; macaco preto; uma das espécies de macaco encontradas em território brasileiro. Do tupi: $\mathrm{kai}^{13}$

Maraca indecl. Maracá; instrumento musical; chocalho. Do tupi maraka. ${ }^{14}$

Citamos outra característica do léxico latino em $H N B$ : a presença de palavras clássicas para designar conceitos e itens culturais novos, ou seja, um vocabulário latino antigo que foi ressignificado. Em seu artigo "Neo-Latin Studies: Significance and Prospects", Hans Helander (2001) observa que o uso do latim em obras produzidas durante a primeira geração de humanistas renascentistas foi influenciado, inicialmente, por um certo ideal de pureza clássica. Durante determinada fase da Renascença, vários eruditos disputavam entre si a verdade acerca do ideal de linguagem definido por Cícero, até que esse debate foi ultrapassado, abrindo caminho para estilos menos ortodoxos. Além disso, havia peculiaridades de linguagem de disciplinas coexistentes, cujas convenções mudavam constantemente.

Embora os autores da época soubessem disso, tal pluralidade não foi devidamente levada em consideração pelas pesquisas sobre literatura novilatina, porque os estudos privilegiavam, comumente, obras beletrísticas e, em especial, textos da época heroica da Renascença, isto é, do desenvolvimento e difusão do Renascimento ao longo dos séculos XV e XVI. Com base em nosso levantamento de topônimos e nas afirmações de Helander, concluímos que o tradutor de $H N B$ poderia ser considerado como pertencente a uma geração de autores renascentistas de transição, uma vez que utiliza tanto palavras latinas novas (neologismo de forma) quanto clássicas (neologismo de sentido ${ }^{15}$ para designar objetos e conceitos modernos, ou seja, não se submete às prescrições lexicais dos ciceronianos ortodoxos nem tão pouco abandona de todo o léxico antigo.

Na verdade, essa orientação quanto ao uso do latim é fundamento da linguagem científica, que antepõe as necessidades de comunicação internacional ao rigor dos princípios restauradores da língua clássica, apregoados pelos ciceronianos ortodoxos. Podemos recuperar a essência dessa nova orientação por meio dos Historiarum ab inclinatione Romanorum imperii decades, de Flavio Biondo (1483), importante obra sobre historiografia moderna escrita na Renascença italiana. Nela, Biombo tece considerações sobre a linguagem historiográfica de sua época, que revelam a perspectiva dos ciceronianos moderados e que resumimos em três pontos: 1) a latinitas depende da elegância (elegantia) da composição e do estilo apropriado (dignitas), daí que as palavras devem ser usadas em seu significado original (proprietas), evitando-se a deterioração do latim; por outro lado, 2) a imitação cega dos clássicos pode levar ao absurdo, pois as realidades sociais e políticas na Itália mudaram desde a Antiguidade; portanto, 3) preservar integralmente as formas de expressão dos autores antigos é um contrassenso, mas o leitor moderno habituado à escrita clássica esperaria linguagem semelhante em uma obra moderna, o que conduz a um grande dilema: escrever em latim

\footnotetext{
${ }^{13}$ Cay apenas aparece no texto nas funções de sujeito e objeto direto. A morfologia é a mesma nas duas funções, o que nos impossibilita afirmar que este vocábulo pertence a uma declinação possível na língua latina. Optamos, portanto, tratar vocábulos como este como indeclináveis.

${ }_{14}$ Muitas das palavras utilizadas para compor o corpus deste trabalho têm influência da língua tupi. Portanto julgamos relevante apontar no glossário quando uma palavra que aparece em $H B N$, na verdade, é uma palavra ouvida a partir dos nativos e utilizada pelo autor da obra como uma palavra "latinizada".

15 De acordo com Borba (2003, p. X), neologismos de sentido consistem em palavras que sofrem um processo de expansão semântica, em que aos significados antigos mesclam-se novos. Neologismos de forma, por sua vez, resultam da expansão do conhecimento, avanço tecnológico, contato com culturas estrangeiras e mudanças doutrinais, que demandam a criação de novos signos verbais.
} 
clássico e parecer obscuro, ou adotar uma linguagem moderna e parecer ignorante da Antiguidade?

Em síntese, Biombo defende, ao mesmo tempo, que se evitem corruptelas e barbarismos do latim medieval, restaurando-se a dicção clássica, e que se inaugure uma linguagem para um mundo que precisa de novas palavras. Em sua argumentação, o historiador recorre às palavras de um autor clássico como Horácio, que, em sua Ars poética (v. 72), escreveu que o uso é "ius et norma loquendi" ("lei e norma da fala") de uma língua sempre em mudança.

Com relação aos neologismos de sentido em $H N B$, destacamos a seguir um exemplo ilustrativo:

Aurata, quae meo iudicio ita vocatur, quod in aqua luteo esse colore videatur et auro qua[m] simillima, figura sulmoni proxima est. ${ }^{16}$ (LÉRY, 1586, p. 19).

No excerto acima,sulmoni refere-se, inequivocamente, a um tipo de peixe. No entanto, a consulta a um dicionário de latim clássico revela-nos outro sentido para a referida palavra: Sulmo, -onis s.m. Cidade de Sulmona (terra natal de Ovídio); nome de um guerreiro, Sulmão. ${ }^{17} \mathrm{Se}$, por um lado, o tradutor de $H N B$ empregou palavras novas para designar coisas e conceitos da realidade em que se deu a viagem de Jean de Léry à América, por outro, fez uso também do léxico latino clássico ressignificado. Nesse sentido, buscamos, nas palavras de Burke (2009, p. 89), alguns esclarecimentos sobre o processo tradutório de textos de línguas modernas para o latim, procedimento bastante recorrente na Renascença:

Traduzir obras modernas para o latim apresentava o problema de escrever em um latim que os humanistas considerariam clássico a respeito de fenômenos desconhecidos dos antigos romanos. Os próprios humanistas estavam divididos quanto a essa questão, com os "ciceronianos" opondo-se a neologismos enquanto (...) outros consideravam que algumas novas palavras latinas eram necessárias.

\section{Considerações finais}

Este artigo apresentou o estado atual de nossa pesquisa de Iniciação Científica, intitulada "Glossário de topônimos latinos do Brasil em Historia navigationis in Brasiliam". Até o presente momento, foram levantados topônimos dos dez primeiros capítulos e da epistola de nosso corpus. Os resultados parciais da análise dos dados nos apontam a presença de uma confluência de concepções linguísticas no latim adotado em $H N B$. Percebemos que o tradutor recorre ao léxico latino clássico, embora este seja ressignificado em algumas descrições, mas, nem por isso, se opõe a latinizar palavras de outros idiomas (francês, tupi etc.) ou a usar neologismos de forma criados em latim.

Como vimos, a reação dos não ciceronianos aos ciceronianos ortodoxos abriu campo para que fosse aceita, pelas novas gerações de humanistas, a inclusão de novas palavras que designassem o novo. Assim, os conhecimentos produzidos com as descobertas científicas e explorações pelo mundo, puderam ser difundidos internacionalmente por meio de termos latinos relacionados a toda uma diversidade de culturas, objetos, costumes e paisagens antes desconhecidas. Somente com o contato

\footnotetext{
16 “O dourado, que ao meu parecer, é chamado assim por ser visto na água com cor amarelada semelhante ao ouro, figura próxima ao salmão”.

${ }^{17}$ Veja-se FARIA, 1967.
} 
com obras como $H N B$ podemos mensurar o quanto a língua dos antigos romanos se aproximou do território brasileiro, possibilitando-nos o estudo não apenas da língua, mas também dos fatos históricos e culturais testemunhados por olhos estrangeiros.

Para fins futuros, continuaremos com o levantamento de dados dos demais capítulos e apêndices do livro. Posteriormente, procederemos à análise dos novos dados colhidos para, por fim, elaborarmos o glossário, que virá acompanhado de um texto introdutório acerca da metodologia, objetivos e questões pertinentes à pesquisa.

\section{Referências}

AMARANTE, José. O latim no Brasil após a segunda metade do século XX e a emergência de novos materiais didáticos. In: CRAVO, Cláudia; MARQUES, Susana (Org.). O ensino das línguas clássicas: reflexões e experiências didáticas. 1. ed. Coimbra: Coimbra, 2017, v. 1, p 91-109.

BIONDO, Flavio. Historiarum abinclinatione Romanorum imperiidecades. Veneza: Octavianus Scotus, 1483.

BORBA, Francisco da Silva. Organização de dicionários: uma introdução à lexicografia. São Paulo: Editora Unesp, 2003.

BURKE, Peter. Taduções para o latim na Europa Moderna. in BURKE, Peter; HSIA, R. Po-chia. A tradução cultural nos primórdios da Europa Moderna. Trad. Roger Maioli dos Santos. São Paulo: Editora Unesp, 2009.

CAMARA JR., Joaquim Mattoso. Estrutura da língua portuguesa. $3^{\text {a }}$ ed. Petrópolis: Vozes, 1972.

CARVALHO, Moacyr Ribeiro de.Dicionário tupi (antigo) português. Salvador: BCB, 1987.

FARIA, Ernesto. Dicionário escolar latino-português. $4^{\mathrm{a}}$ ed. Rio de Janeiro: NME, 1967.

Gramática Superior da Língua Latina. Rio de Janeiro: Acadêmica, 1958.

HELANDER, Hans. Neo-latin Studies: Significance and Prospects. Symbolae Osloenses n. 76, 2001, p. 5-102.

HORÁCIO. Arte poética. Introdução e comentários de R. M. Rosado Fernandes. Lisboa: Editorial Inquérito, 1984.

IRIARTE SANROMÁN, Á. A unidade lexicográfica: palavras, colocações, frasemas, pragmatemas. Braga: Centro de Estudos Humanísticos, 2001.

LÉRY, Jean de. Historia navigationis in Brasiliam: qva describitvr avtoris nauigatio, quaeque in mari vidit memoriae prodenda: Villagagnonis in America gesta: Brasiliensium victus \& mores, a nostris ad modum alieni, cum eorum linguae dialogo: animalia etiam, arbores, atque herbae, reliquaque singularia $\&$ nobis penitus incognita. Genève: Suíça, 1586. 

1578 .

Histoire d'un Voyage fait em la terre du Brésil. La Rochelle: Antoine Chuppin,

LOPES, Célia Regina dos Santos et alii. Olhares sobre o português medieval: Filologia, História e Língua. Rio de Janeiro: Vermelho Marinho, 2017.

MARIZ, Vasco; PROVENÇAL, Lucien. Os franceses na Guanabara: Villegagnon e a França Antártica. $3^{\text {a }}$ ed. Rio de Janeiro: Nova Fronteira, 2015.

NUÑEZ GONZÁLEZ, Juan Maria. Ciceronianismo y latin renacentista. Minerva: Revista de filologia clássica, n. 5, 1991. p. 229-258.

SILVA, Edson Nunes da. In CARVALHO, Moacyr Ribeiro de. Dicionário tupi (antigo) português. Salvador: BCB, 1987.

Data de envio: 21-10-2018

Data de aprovação: 20-02-2019

Data de publicação: 05-10-2019 